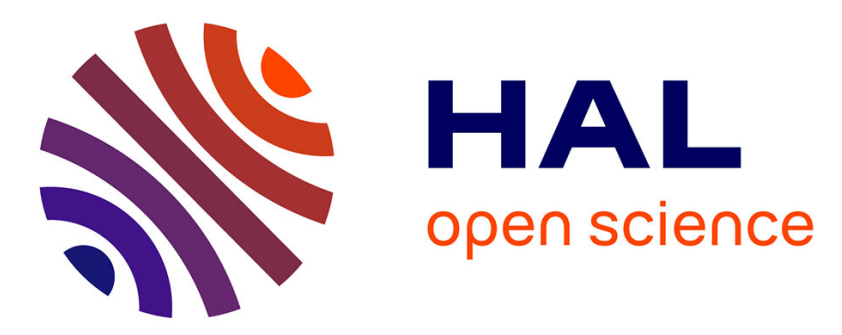

\title{
Molecular weight influence on shape memory effect of shape memory polymer blend (poly(caprolactone)/ styrene-butadiene-styrene )
}

Abir Ben Abdallah, Fehmi Gamaoun, Achraf Kallel, Abbas Tcharkhtchi

\section{To cite this version:}

Abir Ben Abdallah, Fehmi Gamaoun, Achraf Kallel, Abbas Tcharkhtchi. Molecular weight influence on shape memory effect of shape memory polymer blend (poly(caprolactone)/ styrene-butadiene-styrene ). Journal of Applied Polymer Science, 2021, 138 (5), pp.1-11. 10.1002/app.49761 . hal-03160338

\section{HAL Id: hal-03160338 \\ https://hal.science/hal-03160338}

Submitted on 5 Mar 2021

HAL is a multi-disciplinary open access archive for the deposit and dissemination of scientific research documents, whether they are published or not. The documents may come from teaching and research institutions in France or abroad, or from public or private research centers.
L'archive ouverte pluridisciplinaire HAL, est destinée au dépôt et à la diffusion de documents scientifiques de niveau recherche, publiés ou non, émanant des établissements d'enseignement et de recherche français ou étrangers, des laboratoires publics ou privés. 


\title{
Molecular weight influence on shape memory effect of shape memory polymer blend (poly(caprolactone)/ styrene-butadiene-styrene)
}

\author{
Abir Ben Abdallah ${ }^{1,2}$ \\ Fehmi Gamaoun $^{3,4}$ | Achraf Kallel ${ }^{5}$ \\ Abbas Tcharkhtchi ${ }^{1}$
}

${ }^{1}$ Laboratoire PIMM, Arts et Métiers ParisTech, CNRS, Cnam, HESAM

Université, Paris, France

${ }^{2}$ Laboratoire Mécanique de Sousse, Université de Sousse, ENISO, Sousse, Tunisia

${ }^{3}$ Department of Mechanical Engineering, College of Engineering, King Khalid University, Abha, Saudi Arabia

${ }^{4}$ National Engineering School of Sousse, Sousse University, Sousse, Tunisia

${ }^{5}$ Research Center, La Défense, Léonard de Vinci Pôle Universitaire, Paris, France

Correspondence

Abir Ben Abdallah, Laboratoire PIMM,

Arts et Métiers ParisTech, CNRS, Cnam

HESAM Université, Paris, France.

Email: abir.ben_abdallah@ensam.eu

\begin{abstract}
The shape memory effect (SME) does not only concern the macroscopic structure. It concerns also the polymer structure at morphological, macromolecular, and molecular scales. This effect may depend on different physicochemical properties like morphology heterogeneity, chain rigidity, steric hindrance, chain polarity, free volume, cross-linking or entanglement density, molecular shape and weight, and so on. Hence, finding the relationship between the SME and these properties is very important. This can help to obtain the knowledge about the phenomenon origin and mechanism. One of the basic polymer properties, which can have direct SME, may be the molecular weight $\left(M_{\mathrm{w}}\right)$. The question here is: If the $M_{\mathrm{w}}$ of a shape memory polymer (SMP) changes, for different reasons like degradation, what will be the effect of this change on its SME. In order to answer to this question, the investigation is focused on an SMP blend of $40 \%$ poly( $\epsilon$-caprolactone) (PCL) and 60\% styrene-butadienestyrene (SBS). Then, enzymatic hydrolysis is performed on this blend to change its $M_{\mathrm{w}}$. It is shown that this change is only related to the variation in the $M_{\mathrm{w}}$ of PCL. After that, different samples with a distinct average $M_{\mathrm{w}}$ are prepared and characterized by various experimental methods. Shape memory tests are performed on these blends, and the recovery rate $\left(R_{\mathrm{r}}\right)$ for each of them is determined. It is found that when $M_{\mathrm{w}}$ of PCL decreases, its degree of crystallinity, its glass transition, and its melting temperatures, corresponding to the PCL phase, increase. However, the elongation at break of the blend declines with the reduction in $M_{\mathrm{w}}$. The tests show that the alteration in the blend's $M_{\mathrm{w}}$ influences its SME. Indeed, $R_{\mathrm{r}}$ of the (PCL/SBS) mixture drops with the decrease in $M_{\mathrm{w}}$ of PCL.
\end{abstract}

\section{K E Y W O R D S}

degradation, mechanical properties, stimuli-sensitive polymers, thermal properties, blends

\section{1 | INTRODUCTION}

Shape memory polymers (SMPs) constitute a range of smart materials. They have the capacity to deform to a temporary shape and to recover their permanent shape when exposed to a specific stimulus such as temperature. ${ }^{1,2}$ This behavior applies to a wide range of SMP applications. For instance, SMPs are essentially used in 
the design of biomedical devices, like sutures and microactuators. ${ }^{3}$ In addition, these polymers are used in manufacturing self-deployable equipment in spacecraft, ${ }^{4}$ smart textiles, ${ }^{5}$ heat shrinkable packages, tubing, sensor, and actuators. ${ }^{6,7}$

For thermal trigging, the shape memory effect (SME) is obtained under the application of a specific cycle. This cycle consists of heating, deformation, relaxation, fixing, and recovery. ${ }^{8}$

At the microstructural scale, the SME is caused by the variation in the molecular mobility in the polymer structure. When the SMP is in its permanent shape, when the temperature is low, the chains are stable with a very low molecular motion. At high temperatures, the mobility of chains increases. Then, by applying an external force, the arrangement of these chains varies, leading to a decrease in the entropic state of the polymer, followed by a change in its shape. By cooling down the material, this entropic state is blocked, which allows the fixation (or freezing) of a temporary form. Now, if the SMP is reheated, the mobility of chains is activated again, leading to the increase in the entropy of the SMP. As a result, the SMP returns to its original form. ${ }^{7}$ The ability of a thermosensitive SMP to change from a permanent shape to a temporary one and vice-versa could be explained by the presence of two different phases: hard and soft, with different mechanical properties. The hard segments represent the regions with high intermolecular adhesion and ensure the shape stability, hence maintaining the original form. However, the soft segments represent the switch, thus ensuring the shape change. ${ }^{7}$

For a shape memory blend, two immiscible polymers, one representing the hard phase and another representing the soft one, can be mixed to form a new polymer with SME. ${ }^{9,10}$ For example, poly(€-caprolactone) (PCL), which is a semicrystalline biodegradable aliphatic polyester, can be blended with styrene-butadiene-styrene (SBS) to form a new polymer with an SME. In this case, PCL represents the hard segments and SBS represents the soft ones.

Recent research ${ }^{8,11}$ on SMPs has shown that the SME might be related to the irreversible microstructure alterations. Accordingly, even the SMP retains its SME, it will lose its initial properties, depending on its microstructure. In fact, the SME is one of the properties of SMPs which may be related to some other properties like the heterogeneity of the polymer morphology, viscoelasticity, degree of physical and chemical cross-linking, free volume fraction, and so on. In macromolecular and molecular scales, it depends on the chain structure, the molecular weight $\left(M_{\mathrm{w}}\right)$, the chain rigidity and the chain polarity, etc. It is then very important to find these properties and to investigate on this relationship. This investigation can help to find the origin of the SME and to understand its mechanism.

Between different polymer properties, the role of the $M_{\mathrm{w}}$ is very specific because many other properties depend on it. The question is what will be the relationship between this parameter and the SME?

Several studies on SMPs ${ }^{12-14}$ have revealed that the variation in the $M_{\mathrm{w}}$ influences their mechanical and viscoelastic properties, and hence their shape memory properties, particularly in recovery and fixing steps. For example, Retna and Karger-Kocsis ${ }^{6}$ verified that a better SME was obtained for thermoplastic shape memory polyurethane with a percentage of hard segments between $35 \%$ and $40 \%$.

For a PCL/SBS blend, under study, some samples with different molecular weights have been prepared with accelerated enzymatic hydrolysis, which represents the principal degradation mechanism of aliphatic polyesters such as PCL which is a biodegradable polymer. ${ }^{15}$ The enzymatic hydrolysis of PCL starts with a water absorption step followed by the hydrolytic fractionation of the ester bonds. This leads to molecular fragmentation and chain splitting. As a result, the $M_{\mathrm{w}}$ of PCL drops due to this enzymatic hydrolysis. ${ }^{15-19}$ Different tests have been performed on these samples. It has been shown that the hydrolytic degradation of PCL generates the alteration of its transition and melting temperatures and of its crystallinity degree $\left(X_{\mathrm{c}}\right) \cdot{ }^{20-22}$ This degradation causes also the alteration of its mechanical properties such as the Young modulus, the tensile strength, and the strain at break. $^{20,23-25}$ It has been also demonstrated that the change in the $M_{\mathrm{w}}$ can modify the SME of this blend. Based on these results, the relationship between the SME and the $M_{\mathrm{w}}$ has been discussed.

\section{2 | MATERIALS AND METHODS}

A blend of (40\%) PCL and (60\%) SBS is studied. By preliminary studies, it is shown that this mixture with this proportion between the components has a 100\% SME.

PCL used for this study is CAPA 6800 PCL and is supplied by Perstrop Limited UK. This polymer is a semicrystalline biodegradable thermoplastic with a glass transition temperature of $-40^{\circ} \mathrm{C}$ and $X_{\mathrm{c}}$ of nearly $50 \%$. It has a relatively low melting point between $58^{\circ} \mathrm{C}$ and $61^{\circ} \mathrm{C}$. The SBS, provided by Sinopec Group, is an amorphous block copolymer whose chain is formed by butadiene groups in the middle and styrene groups in both sides. SBS is an elastomer with a glass transition temperature of $-80^{\circ} \mathrm{C}$. Forty percent of PCL and sixty percent of SBS are initially extruded through a twin-screw extruder machine (Brabender, Duidburg Germany). For 
mechanical and shape memory tests, the extruded pellets are introduced into an injection machine to get final specimens with a gauge size of $25 \times 4 \times 2 \mathrm{~mm}^{3}$.

To determine the average $M_{\mathrm{w}}$ and to characterize the molecular weight distribution (MWD) of polymer chains, gel permeation chromatography (GPC) is carried out using a Waters GPC machine. GPC can measure a wide range of molecular weights including the number average molecular weight $\left(M_{\mathrm{n}}\right)$, the $M_{\mathrm{w}}$, and the polydispersity index $(I) .{ }^{26,27}$ For this study, we use tetrahydrofuran (THF) since PCL can easily be diluted in THF. GPC is a relative method that requires calibration using the $M_{\mathrm{w}}$ curve of a standard polymer. Therefore, polystyrene, with known molecular weights, is used as the standard.

In order to measure the crystallization and the melting temperatures ( $T_{\mathrm{c}}$ and $T_{\mathrm{m}}$ ), differential scanning calorimetry (DSC) tests are performed using a DSC machine, Q1000 V9.0 Build 275TA Instruments, at a constant ramp of $5^{\circ} \mathrm{C} / \mathrm{min} . T_{\mathrm{c}}, T_{\mathrm{m}}, \Delta H_{\mathrm{c}}$, and $\Delta H_{\mathrm{m}}$ are determined from the first heating / cooling and the second heating curves. Parameter $X_{\mathrm{c}}$ presents the degree of crystallinity and it is given by the following equation:

$$
X_{\mathrm{c}}=\frac{\Delta H_{\mathrm{m}}}{\Delta H_{\mathrm{m} 0}} \times 100,
$$

where $\Delta H_{\mathrm{m}}$ is the melting enthalpy from DSC tests, and $\Delta H_{\mathrm{m} 0}$ is the enthalpy of pure crystalline $(100 \%) \mathrm{PCL}$ which has the value of $142 \mathrm{j} / \mathrm{g}$. ${ }^{28}$

Dynamical mechanical analysis (DMA) experiments are carried out, using a DMA Q800 TA Instruments type machine, to investigate the glass transition temperature $\left(T_{\alpha}\right)$ of the blend. All DMA tests are performed with a temperature range between $-100^{\circ} \mathrm{C}$ and $100^{\circ} \mathrm{C}$, a heating ramp of $5^{\circ} \mathrm{C} / \mathrm{min}$, and a frequency of $1 \mathrm{~Hz}$.

The mechanical properties of the blend are evaluated via uniaxial tensile tests using an Instron testing 5566-type machine with a load cell of $10 \mathrm{KN}$. The tests are performed at room temperature with a deformation rate of $6 \mathrm{~mm} / \mathrm{min}$. This tensile machine is equipped with a camera to measure the deformation of the sample. The stress as a function of the strain is then recorded.

To investigate the SME of the blend (40\% PCL/60\% SBS), shape memory tests has been performed. A typical shape memory cycle consists of the following steps: (a) heating the sample until $50^{\circ} \mathrm{C}$; (b) extending to a certain strain; (c) fixing the shape at this deformation by cooling down the sample from $50^{\circ} \mathrm{C}$ to the room temperature; (d) unloading the sample to zero stress and then recording the strain; and (e) recovery test, which means heating up again the unloaded sample to a temperature of $58^{\circ} \mathrm{C}$ and then recording the strain (recovery test).
In order to have different samples with various molecular weights, enzymatic hydrolysis is carried out on this blend. For that, the samples of the PCL/SBS blend are immersed in a solution of distilled water, phosphate buffered saline (PBS) and amano lipase from pseudomonas fluorescence $(2.5 \mu \mathrm{g} / \mathrm{mL})$. To preserve the enzyme activity, the solution is changed twice a week. The pseudomonas enzyme and PBS are provided by Sigma Alderich. At specific periods of time, specimens are removed and dried under vacuum.

\section{3 | RESULTS AND DISCUSSIONS}

\section{1 | Materials characterization before hydrolysis}

GPC tests are carried out to evaluate the $M_{\mathrm{w}}$, using THF as a solvent. Knowing that only PCL can be dissolved in THF, GPC then will give the MWD diagram (Figure 1) to determine $M_{\mathrm{n}}, M_{\mathrm{w}}$, and $I$ of PCL in the blend using the following equations (Table 1):

$$
M_{\mathrm{n}}=\frac{\sum N_{i} M_{i}}{\sum N_{i}}
$$

$$
M_{\mathrm{w}}=\frac{\sum N_{i} M_{i}^{2}}{\sum N_{i} M_{i}}
$$

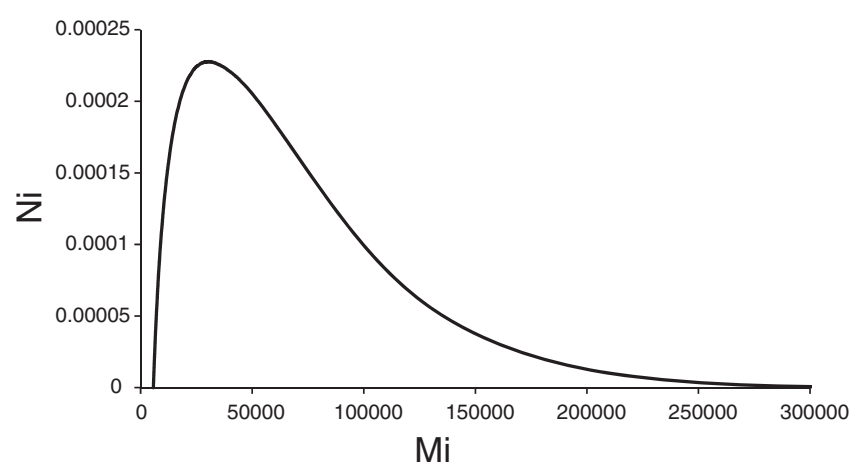

F I G U RE 1 MWD curve of PCL. MWD, molecular weight distribution; PCL, poly(e-caprolactone)

T A B LE $1 \quad M_{\mathrm{w}}$ and $I$ of PCL in SBS/PCL blend

\begin{tabular}{llll} 
Material & $\boldsymbol{M}_{\mathbf{w}}$ [g/Mol] & $\boldsymbol{M}_{\mathbf{n}}$ [g/Mol] & $\boldsymbol{I}$ \\
SBS (60\%) / PCL (40\%) & 71,220 & 41,970 & 1.69 \\
\hline
\end{tabular}

Abbreviations: PCL, poly( $\epsilon$-caprolactone); SBS, styrene-butadienestyrene. 


$$
I=\frac{M_{W}}{M_{n}},
$$

where $N_{i}$ is the number of macromolecules, and $M_{i}$ is the $M_{\mathrm{w}}$.

According to GPC results, PCL has $M_{\mathrm{w}}$ of $71,220 \mathrm{~g} / \mathrm{mol}$ and $M_{\mathrm{n}}$ of $41,970 \mathrm{~g} / \mathrm{mol} . M_{\mathrm{n}}$ is associated to the colligative characteristics of materials. $M_{\mathrm{w}}$ is associated to the bulk and physical properties of materials. When we refer to $M_{\mathrm{w}}$ in terms of polymer, we actually refer to the length of individual chains. PCL used in this study has a relatively high $M_{\mathrm{w}}$, which is associated to longer chains and higher degrees of entanglement. ${ }^{29}$ The $M_{\mathrm{w}}$ to $M_{\mathrm{n}}$ ratio determines $I$ which represents the width of the distribution of the molecular range. For PCL, $I$ is equal to 1.69 . This outcome means that PCL has a medium width distribution as its $I$ is between 1.2 and 2 .

Practically, the average molecular weights $\left(M_{\mathrm{w}}\right.$ and $M_{\mathrm{n}}$ ) and the molecular distribution have a significant impact on the polymer viscoelastic and physicalmechanical properties like toughness, elasticity, and transition temperature. The mechanical properties of polymers (modulus of elasticity, resistance, and maximum deformation) are influenced by the MWD, by the weight average $M_{\mathrm{w}}$ and by the polydispersity index. Different researchers and research teams have demonstrated this impact. For example, Shinozaki et al., ${ }^{30}$ reported that the tensile strength and Young's modulus increase with $M_{\mathrm{w}}$ for poly(vinyl chloride) (PVC). In another study on polyethylene, G. Capaccio et al., ${ }^{31}$ showed that the elastic modulus rises with the increase of the polydispersity.

At the microstructure scale, the relationship between the $M_{\mathrm{w}}$ and the mechanical properties can be shown by the following formula ${ }^{32}$ :

$$
G_{\mathrm{c}}=R T \rho / M_{\mathrm{E}}
$$

with $\mathrm{G}_{\mathrm{c}}=$ shear modulus, $M_{\mathrm{E}}=$ molecular weight between entanglement, $T=$ absolute temperature, $\rho=$ density.

Concerning the viscoelasticity of polymers, the effect of $M_{\mathrm{w}}$ on the viscosity is also very important. This relation is given by a power law of type:

$$
\eta=K \cdot M^{\mathrm{a}}
$$

with $h=$ viscosity, $M=$ weight average $M_{\mathrm{w}}$ and $K$ and $a=$ constants.

DSC experiments are carried out in a temperature range between room temperature and $70^{\circ} \mathrm{C}$, according to the procedure explained before determining the thermal properties of the materials. The results are presented in Figure 2.

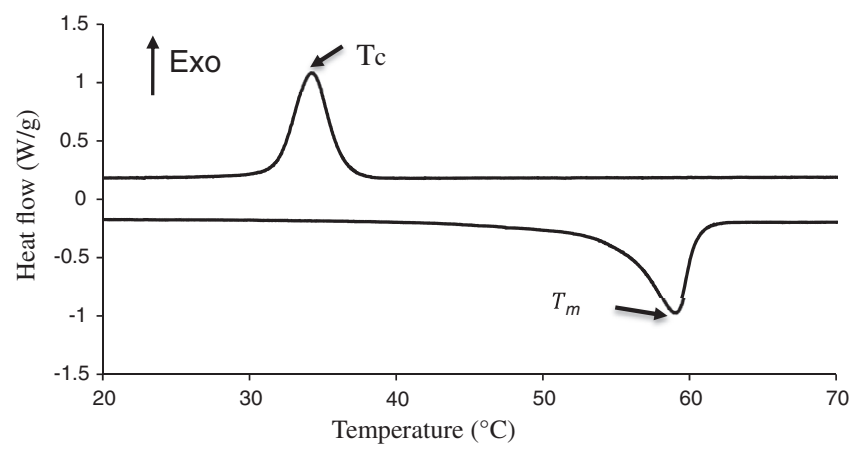

F I G U R E 2 DSC curve of blend. DSC, differential scanning calorimetry

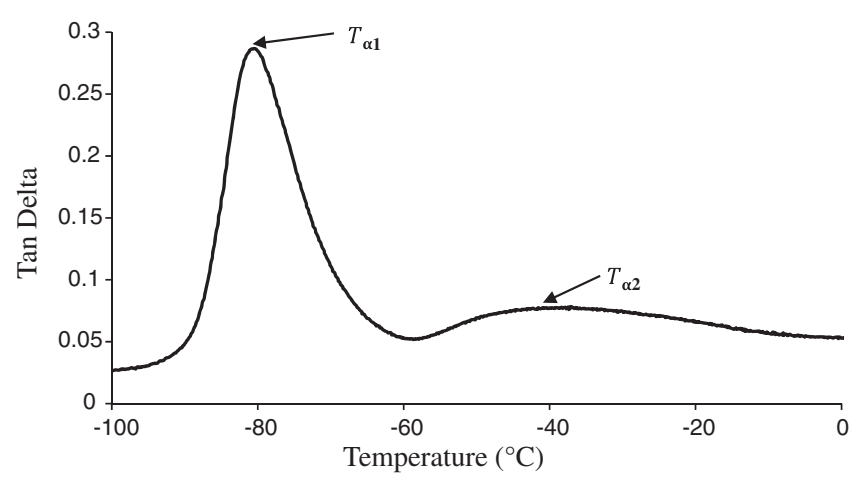

F I G URE 3 DMA results of blend. DMA, dynamical mechanical analysis

According to these results, during heating, the peak presented at $59^{\circ} \mathrm{C}$ corresponds to the melting point $T_{\mathrm{m}}$ of PCL and during cooling; the peak at 34 represents its crystallization temperature $T_{\mathrm{c}}$. Actually, $X_{\mathrm{c}}$ of the blend is calculated from Equation (1) and is almost $51.4 \%$. It is important to mention that as SBS is an amorphous elastomer, it does not dispose of crystallization or melting temperatures. Also, the ratio of SBS in the blend is not considered in calculation of the blend $X_{\mathrm{c}}$. Thus, $T_{\mathrm{c}}, T_{\mathrm{m}}$, and $X_{\mathrm{c}}$ of the blend are only related to the PCL phase. ${ }^{33}$

Then, DMA tests are performed on a virgin blend. Figure 3 illustrates tan $\delta$ versus temperature of the blend. The peak on this curve gives directly the value of $T_{\alpha}$ which correspondas to the glass transition temperature of polymers in the blend.

According to Figure 3, the (PCL/SBS) blend shows two distinct peaks corresponding to two various glass transition temperatures $T_{\alpha}$ : The first one appears at $-80.7^{\circ} \mathrm{C}\left(T_{\alpha 1}\right)$ which corresponds to the glass transition temperature of SBS, and the second one at $-39.7^{\circ} \mathrm{C}\left(T_{\alpha 2}\right)$ which corresponds to PCL. The existence of these two separate $T_{\alpha}$ evinces that the two polymers forming the blend are immiscible. ${ }^{33}$ These outcomes are in harmony with the work of Zhang et al. ${ }^{9}$ who demonstrated that 
PCL and SBS constituted an immiscible blend that displayed two separate glass transition temperatures $\left(T_{\alpha}\right)$, noting that SBS represents the soft segments of the blend and PCL its hard segments.

The samples are submitted to tensile tests at room temperature with a deformation rate of $6 \mathrm{~mm} / \mathrm{min}$. The results are depicted in Figure 4 and Table 2.

According to these results (Figure 4 and Table 2), the blend displays a young modulus of $116 \pm 3.5 \mathrm{MPa}$, and a fracture stress of $7 \pm 0.5 \mathrm{MPa}$. Its tensile curve until fracture shows two different regions of deformation: The first one consists of an elastic zone (6\%-8\% of deformation) and the second one consists of a plastic zone ( $>10 \%$ of deformation). The blend has a strain at break of $292 \pm 9 \%$. We notice that the (PCL/SBS) blend displays a ductile character since it can undergo a significant plastic deformation before rupture. ${ }^{33}$ The high value of deformation at break and the relatively high ductility of the blend indicate that PCL and SBS are compatible in the blend. Concerning compatibility, Massardier et $\mathrm{al}^{34}$ reported that for the polyamide 6 (PA6) / acrylonitrile butadiene styrene (ABS) mixture, a good compatibility between the blend components would enhance its mechanical properties. They highlighted that when the compatibility of the mixture increased, the young modulus was improved and the elongation to fracture rose. This compatibility can be explained as follows:

- Although the results of DMA, PCL, and SBS are not $100 \%$ immiscible, we can suppose that it forms two phases but with a good adhesion between them at the interface thanks to a partial miscibility.

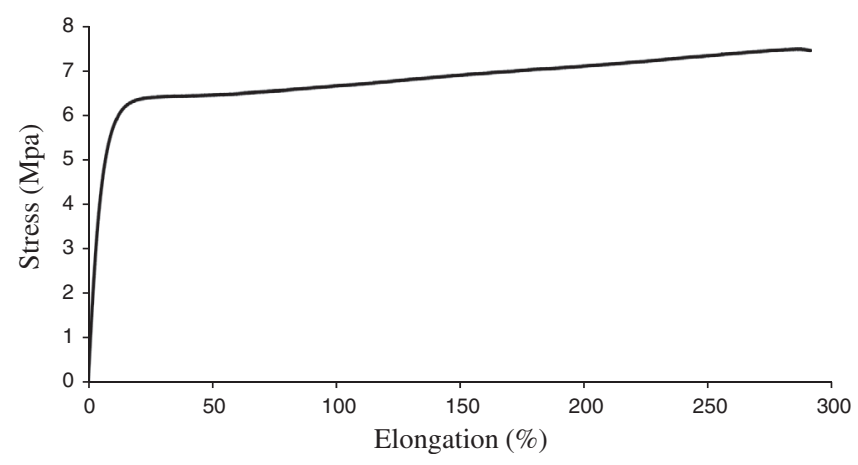

F I G U R E 4 Tensile curve of blend
- Since the amount of PCL is high (40\%), it does not form a dispersed and discontinuous phase in the SBS matrix (60\%). Indeed, the two polymers constitute two continuous phases in the blend.

Shape memory tests are realized following the typical shape memory cycle: deformation (at $T>T_{\alpha}$ ), fixing (at $T=T_{\text {room }}$ ), and recovery (at $T>T_{\alpha}$ ).

In the first step, the tests are performed at different levels of deformation: $25 \%, 50 \%$, and $100 \%$ at $40^{\circ} \mathrm{C}$.

In the second step, the sample is fixed at these rates of deformation by cooling until room temperature.

During the recovery step (Figure 5), the sample is heated at $58^{\circ} \mathrm{C}$, the length of the sample decreases; and due to the SME, the sample recovers its original shape.

This step is evaluated by a parameter called the recovery rate $\left(R_{\mathrm{r}}\right)$. This parameter represents the capacity of the blend to recover its initial shape, and is determined according to the following equation:

$$
R_{r}=\frac{L_{\mathrm{u}}-L_{\mathrm{f}}}{L_{\mathrm{u}}-L_{\mathrm{i}}} \times 100,
$$

where $L_{\mathrm{i}}$ is the initial sample length, $L_{\mathrm{u}}$ is the length after a tensile test without stress (jaws are released), and $L_{\mathrm{f}}$ is the length after recovery.

According to Figure 5, it can be notice that for all cases the blend shows a total SME; and regardless of the deformation rate, it recovers $100 \%$ of its initial shape.

In fact, when the sample is extended to a $25 \%, 50 \%$, or $100 \%$ strain at $50^{\circ} \mathrm{C}$ (heating + deformation steps), residual stresses are introduced in the blend structure. During

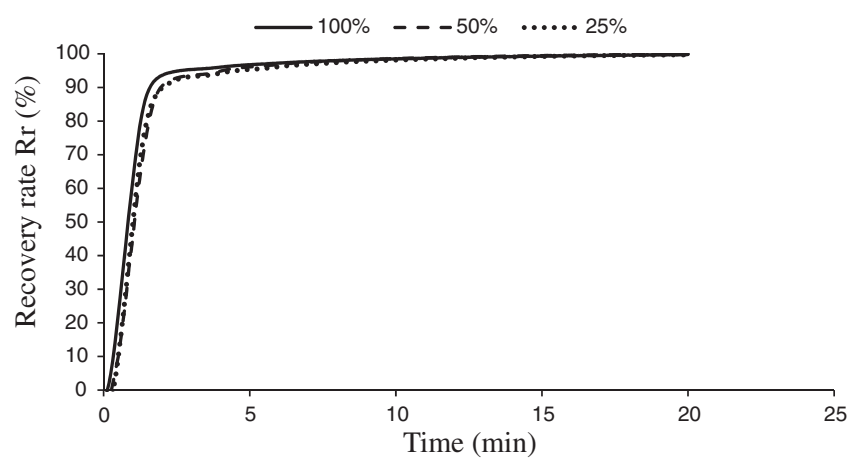

F I G U RE 5 Recovery test at $T=58^{\circ} \mathrm{C}$, for varied deformation

T A B L E 2 Properties of SMP blend (40\% PCL / 60\% SBS)

\begin{tabular}{|c|c|c|c|c|c|c|c|c|c|}
\hline $\begin{array}{l}M_{\mathrm{w} 1}(\mathrm{PCL}) \\
{[\mathrm{g} / \mathrm{Mol}]}\end{array}$ & $\begin{array}{l}M_{\mathrm{n} 1}(\mathrm{PCL}) \\
{[\mathrm{g} / \mathrm{Mol}]}\end{array}$ & $\begin{array}{l}X_{\mathbf{c}} \\
{[\%]}\end{array}$ & $\begin{array}{l}T_{\alpha 1} \\
{\left[{ }^{\circ} \mathbf{C}\right]}\end{array}$ & $\begin{array}{l}T_{\alpha 2} \\
{\left[{ }^{\circ} \mathbf{C}\right]}\end{array}$ & $\begin{array}{l}T_{\mathbf{c}} \\
{\left[{ }^{\circ} \mathbf{C}\right]}\end{array}$ & $\begin{array}{l}T_{\mathbf{m}} \\
{\left[{ }^{\circ} \mathbf{C}\right]}\end{array}$ & $E$ [MPa] & $\varepsilon_{\mathrm{r}}[\%]$ & $\begin{array}{l}\boldsymbol{R}_{\mathbf{r}} \\
{[\%]}\end{array}$ \\
\hline 71,223 & 42,144 & 51.4 & -80.7 & -39.7 & 34.1 & 58.9 & $116 \pm 3.5$ & $292 \pm 9.0$ & 100 \\
\hline
\end{tabular}

Abbreviations: PCL, poly(e-caprolactone); SBS, styrene-butadiene-styrene; SMP, shape memory polymer. 


\begin{tabular}{llll} 
Hydrolysis time [days] & $\boldsymbol{M}_{\mathrm{w}}(\mathbf{P C L})[\mathrm{g} / \mathbf{M o l}]$ & $\boldsymbol{M}_{\mathrm{n}}(\mathbf{P C L})[\mathrm{g} / \mathbf{M o l}]$ & $\boldsymbol{I}$ \\
\hline 0 & $M_{\mathrm{w} \boldsymbol{1}}=71,220$ & $M_{\mathrm{n} \boldsymbol{1}}=42,144$ & 1.69 \\
7 & $M_{\mathrm{w} 2}=68,760$ & $M_{\mathrm{n} \boldsymbol{2}}=39,291$ & 1.75 \\
\hline 15 & $M_{\mathrm{w} \boldsymbol{3}}=66,480$ & $M_{\mathrm{n} \boldsymbol{3}}=34,093$ & 1.95 \\
21 & $M_{\mathrm{w} \boldsymbol{4}}=647,340$ & $M_{\mathrm{n} \boldsymbol{4}}=35,767$ & 1.81 \\
\hline 25 & $M_{\mathrm{w} \boldsymbol{5}}=62,800$ & $M_{\mathrm{n} \boldsymbol{5}}=31,879$ & 1.97 \\
\hline
\end{tabular}

TA B LE $3 \quad M_{\mathrm{w}}$ and $M_{\mathrm{n}}$ values depending on hydrolysis time

Abbreviation: PCL, poly( $\epsilon$-caprolactone).

fixing, the material is cooled down and these stresses are stored in the SMP structure. Next, at the recovery step, when the sample is heated again, these internal stresses are released and the material recovers its initial shape due to its shape memory property. As the temperature increases, the chains become more flexible and their mobility grows, which facilitates shape recovery. For this SMP blend, PCL, which represents the hard segments, ensures shape stability, and SBS, which represents the soft segments, ensures shape changes.

The SME can be explained by the variation in the molecular mobility inside the polymer. Indeed, while the SMP is in its permanent shape, the chains are in a stable thermodynamic state. However, at a high temperature, the chains become more flexible; and by applying an external stress, the chains arrangement varies and causes a reduction in the entropic state of the polymer followed by a change in its form. By cooling down the material, this entropic state is blocked and allows the fixation of the temporary shape. Finally, by heating again the SMP blend, the mobility of the chains is reactivated, and the polymer regains its initial shape. ${ }^{35}$

To evaluate $M_{\mathrm{w}}$ and MWD of the PCL and to determine the influence of these properties on the viscoelastic and physical-mechanical properties of the blend, GPC, DSC, DMA, and tensile experiments are performed according to the procedure explained before. These experiments are followed by shape memory tests in order to examine the SME of the blend. All results are recapitulated in Table 2. The existence of two separate glass transition temperatures, $T_{\alpha 1}$ corresponding to the SBS phase and $T_{\alpha 2}$ corresponding to the PCL phase, confirms the immiscible or weak partial immiscible character of polymers in the blend. This immiscibility can be explained also by high $X_{\mathrm{c}}$ of the blend. The results of tensile tests indicate that the blend displays a ductile character. Usually, a high $M_{\mathrm{w}}$ means an elevated degree of entanglement in the amorphous phase. ${ }^{36}$ These entanglements permit the polymer to be stretched more before the rupture of chains. This could be explained by the fact that a raised degree of entanglement implies that there are more polymer bonds that need to be broken, which allows the polymer to absorb more energy before fracture.

In addition, DSC experiments reveal that $T_{c}$ and $T_{m}$ of the blend corresponds to the PCL phase, which confirms the mixture compatibility. This compatibility can explain the good recovery of the permanent shape. Furthermore, according to Table 3, PCL used in the blend has a relatively high molecular weight $\left(M_{w} \simeq 71\right.$ $\mathrm{Kg} / \mathrm{mol}$ ). Generally, this parameter is related to longer chains of hard segments and the existence of intermolecular hydrogen bonds. ${ }^{36}$ This provides more stability of physical crosslinks, leading to high $R_{r}$. Shape memory tests confirm this outcome as the (SBS/PCL) blend under study has a recovery rate of $100 \%$. Moreover, longer chains are more flexible and their deformation is easier at $\mathrm{T}>T_{\alpha 2}$. As a result, the SMP exhibits a better SME.

\section{2 | Change in PCL $M_{\mathrm{w}}$ by enzymatic hydrolysis}

In order to change the $M_{\mathrm{w}}$ of PCL and to get blend samples with varied $M_{\mathrm{w}}$ of PCL, enzymatic hydrolysis ${ }^{33}$ is performed according to the protocol described in the previous section. Multiple samples, aged at different time, are obtained in this way. Virgin and aged samples are then tested by GPC according the procedure explained above. Figure 6 outlines the MWD curves of PCL before and after 25 days of hydrolysis, and Table 3 shows the values of $M_{\mathrm{w}}, M_{\mathrm{n}}$, and $I$ obtained by GPC tests.

According to these results, one can notice an enlargement of the PCL MWD, which means the increase in $I$ and the decrease in $M_{\mathrm{w}}$ during hydrolysis. $M_{\mathrm{w}}$ passes from 71,220 to $66,480 \mathrm{~g} / \mathrm{mol}$ after 15 days. After 25 days of hydrolysis, it has the value of $62,800 \mathrm{~g} / \mathrm{mol}$. At the same time, $I$ rises from 1.69 to 1.97 at the end of hydrolytic degradation. This polydispersity growth is associated to an enlargement of the MWD curves of PCL. The decrease in $M_{\mathrm{w}}$ could be explained by the scission of 
chains due to hydrolysis, as $M_{\mathrm{w}}$ gives an indication of the length of chains. In fact, enzymatic hydrolysis starts with hydrolytic fractionation of ester bonds, which induces a molecular fragmentation. This chain splitting leads to the decline in entanglement density within the PCL structure. The reduction in chain entanglement may have a consequence on the mechanical properties of polymers. Tsuji and Ishizaka ${ }^{37}$ realized the enzymatic hydrolysis of pure PCL and PCL/PLLA (Poly-L-Lactide) mixture using a lipase from Rhizopus arrhizus. They noted that the hydrolysis of pure PCL was more significant than that of the PCL/PLLA mixture. They also reported that the MWD of PCL is slightly widened and its $M_{\mathrm{w}}$ decreases after 15 days of enzymatic hydrolysis.

\section{3 | Effect of molecular weight on blend properties and on its SME}

\subsection{1 | Effect of molecular weight on some blend properties}

Different blend samples with different $M_{\mathrm{w}}$ are submitted to various experiments. DSC, DMA, and tensile tests are performed, following the same protocols described in section 2 .

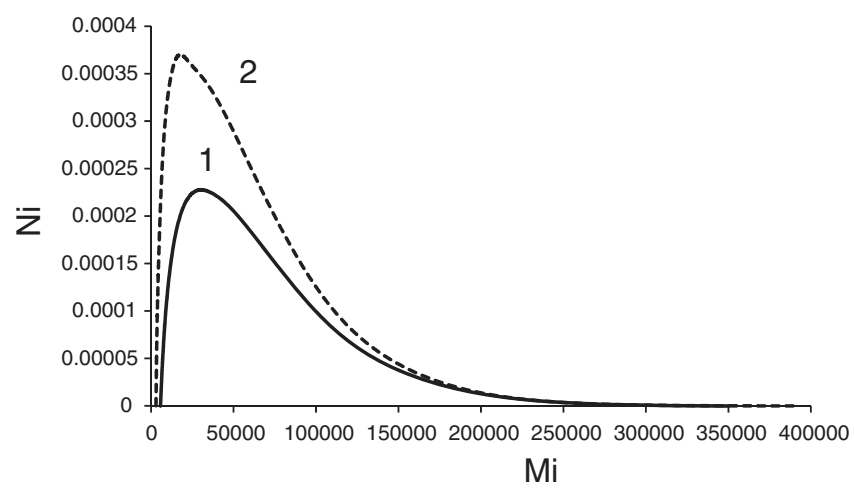

F I G U RE 6 MWD curve of PCL: Before hydrolysis (1) and after 25 days (2). MWD, molecular weight distribution; PCL, poly (€-caprolactone)
Table 4 summarize the evolution of the blend's physical and mechanical properties depending on $M_{\mathrm{w}}$ of PCL.

From these results, we can have the following comments:

- The glass transition temperature of SBS remains relatively constant; that is, SBS is not affected by enzymatic aging. Only PCL is hydrolyzed, and its glass transition temperature $\left(T_{\boldsymbol{\alpha} 2}\right)$ changes from $-39.7^{\circ} \mathrm{C}$ to $33.1^{\circ} \mathrm{C}$. As a result, the gap between the two transition temperatures goes up and consequently the heterogeneity of blend constituents rises.

- The relationship between the $M_{\mathrm{w}}$ and the glass transition temperature may be given by the Fox Flory equation:

$$
T_{\boldsymbol{\alpha}}=T_{\boldsymbol{\alpha} \infty}-\frac{K_{\mathrm{ff}}}{M_{\mathrm{n}}}
$$

Figure 7 shows the variation in $T_{\boldsymbol{\alpha}}$ versus $1 / M_{\mathrm{n}}$. With a correlation coefficient far from $1\left(R^{2}=0.91\right)$, it is difficult to say that this variation follows a straight line. The deviation of this variation from the Fox Flory equation may be explained by the presence of SBS in the structure

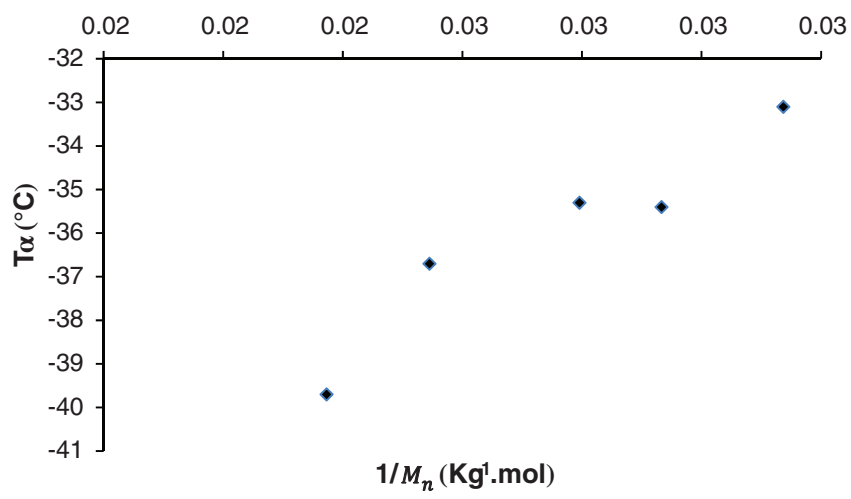

FIG URE 7 Variation in $T_{\boldsymbol{\alpha}}$ versus $1 / M_{\mathrm{n}}$ [Color figure can be viewed at wileyonlinelibrary.com]

TA B L E 4 Dependence of blend properties on $M_{\mathrm{w}}$

$\begin{array}{lllllllll}\boldsymbol{M}_{\mathbf{w}}[\mathbf{g} / \mathbf{M o l}] & \boldsymbol{M}_{\mathbf{n}}[\mathbf{g} / \mathbf{M o l}] & \boldsymbol{T}_{\mathbf{\alpha} 1}\left[{ }^{\circ} \mathbf{C}\right] & \boldsymbol{T}_{\mathbf{\alpha} 2}\left[{ }^{\circ} \mathbf{C}\right] & \boldsymbol{T}_{\mathbf{m}}\left[{ }^{\circ} \mathbf{C}\right] & \boldsymbol{T}_{\mathbf{c}}\left[{ }^{\circ} \mathbf{C}\right] & \boldsymbol{X}_{\mathbf{c}}[\%] & \boldsymbol{\varepsilon}_{\mathbf{r}}[\%] & \boldsymbol{E}[\mathbf{M P a}] \\ M_{\mathrm{w} 1}=71,220 & M_{\mathrm{n} 1}=42,144 & -80.7 & -39.7 & 58.9 & 34.1 & 51.4 & 292 \pm 9.0 & 116 \pm 3.5 \\ M_{\mathrm{w} 2}=68,760 & M_{\mathrm{n} 2}=39,291 & -81.8 & -36.7 & 59.0 & 35.7 & 61.0 & 294 \pm 9.0 & 144 \pm 4.5 \\ M_{\mathrm{w} 3}=66,480 & M_{\mathrm{n} 3}=34,093 & -79.7 & -35.4 & 59.2 & 35.9 & 66.1 & 123 \pm 4.0 & 141 \pm 4.5 \\ M_{\mathrm{w} 4}=64,740 & M_{\mathrm{n} 4}=35,767 & -80.5 & -35.3 & 59.4 & 36.0 & 67.7 & 75 \pm 2.5 & 219 \pm 7.0 \\ M_{\mathrm{w} 5}=62,800 & M_{\mathrm{n} 5}=31,879 & -79.9 & -33.1 & 59.6 & 36.1 & 69.7 & 61 \pm 2.0 & 187 \pm 6.0\end{array}$


of the blend and the effect of its amorphous morphology on PCL.

- It is seen that $T_{\mathrm{m}}$ is almost the same for all samples with different molecular weights, and the change in $T_{\mathrm{c}}$ is negligible, but the variation in $X_{\mathrm{c}}$ is relatively important. According to Table 4, $X_{\mathrm{c}}$ of the blend increases with the decrease in $M_{\mathrm{n}}$ of PCL. For instance, $X_{\mathrm{c}}$ passes from $51.4 \%$ to $69.7 \%$ when $M_{\mathrm{w}}$ of PCL falls from $71,220 \mathrm{~g} / \mathrm{mol}$ to $64,740 \mathrm{~g} / \mathrm{mol}$. Indeed, lower $M_{\mathrm{w}}$ means shorter PCL chains. The latter display more end groups that rise molecular mobility. Consequently, increasing chain mobility facilitates reorientation and recrystallization. Also, the growth of $T_{\boldsymbol{\alpha}}$, as explained before, could be associated to the rise in $X_{\mathrm{c}}$ and the improvement of the cohesion forces in the structure. The buildup of intermolecular interactions, which depict the cohesive forces between materials chains, could be explained by the development of crystallinity. In fact, the increase in crystallinity engenders the reinforcing cohesion of the polymer.

- The growth of $X_{\mathrm{c}}$ engenders the decline in the blend phase's compatibility. Moreover, we remark that the strain at break $\varepsilon_{\mathrm{r}}$ of the mixture drops with the decrease in the $M_{\mathrm{w}}$ ratio of PCL. For example, $\varepsilon_{\mathrm{r}}$ goes down from $292 \%$, for PCL $M_{\mathrm{w}}$ equal to $71,220 \mathrm{~g} / \mathrm{mol}$, to $61 \%$, for PCL $M_{\mathrm{w}}$ equal to $62,800 \mathrm{~g} / \mathrm{mol}$. The drop of PCL $M_{\mathrm{w}}$ causes the reduction in the ductility of the blend. This embrittlement can be explained by the fact that when $M_{\mathrm{w}}$ falls, the degree of chain entanglement decreases too. An elevated degree of entanglement means that there are more bonds that need to be broken, which permits the polymer to absorb more energy before rupture. This outcome is in coherence with the work of B. Fayolle et al. ${ }^{29}$ reported that for an amorphous or semicrystalline polymer, the embrittlement of the structure is related to the decline in the $M_{\mathrm{w}}$ under a critical one due to the reduction in the degree of entanglement. Moreover, the decrease in the elongation to fracture of the blend could be explained by the narrowing of interlamellar spacing due to the elevation of $X_{\mathrm{c} \cdot}{ }^{38}$ Furthermore, results show two different zones, connected by a transition zone. For the sample with high $M_{\mathrm{w}}(>70 \mathrm{Kg} / \mathrm{mol})$, the samples are significantly ductile. But for the low $M_{\mathrm{w}}$ $(<65 \mathrm{Kg} / \mathrm{mol}$ ), the samples become less ductile (brittle). There is a ductile-brittle transition zone between these two zones.

- Table 4 presents also the values of the Young modulus, $E$ of the samples under study. By decreasing $M_{\mathrm{w}}$ from 71,220 to $62,800 \mathrm{~g} / \mathrm{mol}$, we can see the increase in $E$ from $116 \mathrm{MPa}$ to $187-219 \mathrm{MPa}$. The growth of the rigidity of the polymer is essentially caused by the rise in $X_{\mathrm{c}}$. Generally, the amorphous phase is less compact, less rigid, and less impermeable than the crystalline phase. In contact with water, the amorphous phase undergoes degradation (hydrolysis) because water can diffuse into this phase more easily. Due to this degradation, the molar mass decreases. This reduction in the molar mass leads to the increase in chain mobility and promotes the formation of more crystalline zones. It engenders also the increase in the rate of crystallinity. The rise in the elastic modulus $E$ is essentially due to this increase in crystallinity. On the other hand, it can be noted that the strain at break decreases with the decline in the molar mass. The conclusion pinched from this is that as the $M_{\mathrm{w}}$ decreases, $X_{\mathrm{c}}$ rises, leading to an increase in stiffness and tensile strength. ${ }^{39}$ Our outcome is in accordance with the study of Margolies $^{40}$ who indicated that that stiffness was a function of the crystallinity degree. While $M_{\mathrm{w}}$ of polyethylene decreases, $X_{\mathrm{c}}$ and hence stiffness increases. Stiffness continues to rise with the decrease in $M_{\mathrm{w}}$ or the increase in crystallinity.

\subsection{2 | Molecular weight and SME alteration}

To investigate the effect of the decrease in the $M_{\mathrm{w}}$ on the shape memory property of the SMP blend (SBS/PCL), shape memory tests are carried out on the blend with different $M_{\mathrm{w}}$ PCL samples. All tests are performed while respecting the following steps: heating until $50^{\circ} \mathrm{C}, 25 \%$ of deformation, fixing the sample, and recovery at $58^{\circ} \mathrm{C}$. Figure 8 presents the $R_{\mathrm{r}}$ curves for varied $M_{\mathrm{w}}$.

According to Figure 8, the reaction of the blend to thermal heating during the recovery step differs with variable $M_{\mathrm{w}} \cdot R_{\mathrm{r}}$ decreases when $M_{\mathrm{w}}$ of PCL drops. Table 5 denotes the $R_{\mathrm{r}}$ evolution depending on $M_{\mathrm{w}}$.

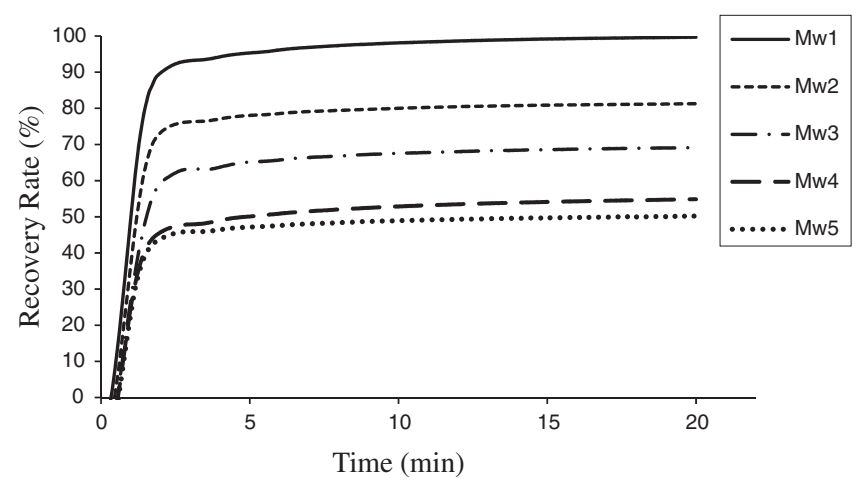

F I G U R E $8 R_{\mathrm{r}}$ curves for different molecular weights 
T A B L E $5 \quad R_{\mathrm{r}}$ depending on $M_{\mathrm{w}}$

\begin{tabular}{ll}
$\boldsymbol{M}_{\mathrm{w}}[\mathrm{g} / \mathrm{Mol}]$ & $\boldsymbol{R}_{\mathrm{r}}[\%]$ \\
$M_{\mathrm{w} 1}=71,220$ & $R_{\mathrm{r} 1}=100$ \\
$\mathrm{M}_{\mathrm{w} 2}=68,760$ & $R_{\mathrm{r} 2}=81$ \\
$M_{\mathrm{w} 3}=66,480$ & $R_{\mathrm{r} 3}=69$ \\
$M_{\mathrm{w} 4}=64,740$ & $R_{\mathrm{r} 4}=55$ \\
$M_{\mathrm{w} 5}=62,800$ & $R_{\mathrm{r} 5}=50$ \\
\hline
\end{tabular}

The results indicate that $R_{\mathrm{r}}$ decreases with decreasing $M_{\mathrm{w}}$. It means that the initial $100 \%$ SMP becomes a partial SMP. ${ }^{41}$ It passes from $100 \%$, for PCL $M_{\mathrm{w}}$ of $71,220 \mathrm{~g} / \mathrm{mol}$, to $69 \%$, for $M_{\mathrm{w}}$ of $66,481 \mathrm{~g} / \mathrm{mol}$. For $M_{\mathrm{w}}$ equal to $62,800 \mathrm{~g} / \mathrm{mol}, R_{\mathrm{r}}$ is equal to $50 \%$. When the $M_{\mathrm{w}}$ of PCL passes from $71,220 \mathrm{~g} / \mathrm{mol}$ to $62,802 \mathrm{~g} / \mathrm{mol}$, the (PCL/SBS) blend with a total SME (TSME) becomes a blend with a partial SME (PSME). The alteration of $R_{\mathrm{r}}$, due to the drop of PCL $M_{\mathrm{w}}$, can be explained by various phenomena.

At first, higher $M_{\mathrm{w}}$ is characterized by longer chains of hard segments and more intermolecular hydrogen bonds, which increases the stability of PCL physical cross linking. Additionally, when $M_{\mathrm{w}}$ is higher, the chains are longer and more flexible, so they can easily be deformed. Therefore, under thermal trigging, the mixture recovers more of its permanent shape. $\mathrm{Xu}$ et al. ${ }^{42}$ studied a SMP based on polyethylene glycol (PEG), as soft segment, and diisocyanate, as hard segments. These hard segments are synthesized using the diisocyanate of biphenyl and the isophorone diisocyanate (IPDI). They stated that the elevation of the molar ratio $r$, of the diisocyanate of biphenyl versus IPDI in the hard phase, induces the augmentation of $R_{\mathrm{r}}$ and owing to the amelioration of interaction in the polymer structure. As a result, the SME is enhanced.

We showed that $X_{\mathrm{c}}$ of the mixture goes up while the $M_{\mathrm{w}}$ of PCL drops. This rising of the crystallinity provokes the reduction of the compatibility between the blend's phases. As a result, $R_{\mathrm{r}}$ goes down due to the lower compatibility between hard and soft segments. Lee and al. ${ }^{43}$ reported that the crystallinity of polyols would influence the separation between hard and soft segments. Indeed, higher crystallinity engenders lower compatibility between mixture segments.

Furthermore, we reveal that $T_{\boldsymbol{\alpha} \mathbf{1}}$, corresponding to the PCL phase, increases when PCL $M_{\mathrm{w}}$ decreases. However, $T_{\mathbf{\alpha} \mathbf{1}}$, corresponding to the SBS phase, remains nearly constant. As a result, the gap between the two transition temperatures rises, hence the immiscibility and heterogeneity of the blend's component growth. Subsequently, the recovery of the SMP blend declines.
Moreover, the decrease in the blend's recovery can be associated to the morphological change in the structure, since the diminution of $M_{\mathrm{w}}$ engenders the drop of the entanglement density and the reduction in the free volume. ${ }^{36}$ The effect of the degree of entanglement in the recovery of the SMP blend will be treated in future work.

In addition, the reduction in $R_{\mathrm{r}}$ can be associated to the augmentation of the hard phase rigidity. In fact, we remark that the Young modulus $E$ increases with the decline of PCL $M_{\mathrm{w}}$. This outcome means that the rigidity of the blend's hard segments rises. Since PCL is the only influenced by enzymatic hydrolysis, $E$ related to the soft segments (SBS) remains the same. However, the SME is related to the presence of two separate phases, hard and soft, with different mechanical properties. It is important to have a compromise between the contributions of these two phases in order to have a better SME. For example, the study of ${ }^{9}$ reported that when the rate of PCL in the blend changed, $R_{\mathrm{r}}$ changed as well. The best $R_{\mathrm{r}}$ was obtained for a PCL proportion between $30 \%$ and $50 \%$. Also, according to our tests, we reveal that a rate of $40 \%$ PCL and $60 \%$ SBS gives $100 \%$ of recovery. These results mean that specific quantities of hard segments (PCL) and soft segments (SBS) should be produced to have maximal $R_{\mathrm{r}}$. For our case, a certain and a specific rigidity of two phases should be present to have a better SME. Thus, the decline in the SME could be explained by the loss of the rigidity of hard segments, while the SBS segments remain constant. The specific influence of the Young modulus on the recovery of the SMP blend will be examined in future work.

The SME, which represents the capacity of the SMP blend to change from a permanent shape to a temporary one and vice-versa, depends on the microstructural properties of the blend components. Indeed, the drop of $M_{\mathrm{w}}$ of PCL engenders the alteration of the morphology, physico-chemical and mechanical properties of the (SBS/PCL) mixture. These changes remain: a reduction in chain lengths, a decrease in entanglement density, an increase in $X_{c}$, a drop of elongation to break, and a rise in both glass transition and melting temperatures. It is obvious that various SMPs such as (SBS/PCL) blends, with different properties, are produced. Then, via shape memory tests, it is shown that these blends have different SMEs, since $R_{\mathrm{r}}$ changes. When $M_{\mathrm{w}}$ passes from 71,220 to $62,802 \mathrm{~g} / \mathrm{mol}, R_{\mathrm{r}}$ is reduced from $100 \%$ to $50 \%$. Thus, the blend is transformed from a TSME material to a PSME one. It is worth mentioning that the PSME represents an intermediate behavior between SMPs and polymers without an SME. This concept is crucial because it helps to create various SMPs in order to meet distinct and specific industrial uses. In any case, the evolution of the SME is very attractive for industry. 


\section{4 | CONCLUSION}

In this paper, the influence of $M_{\mathrm{w}}$ alteration on the SME of a blend consisting of $40 \%$ PCL and $60 \%$ SBS is investigated. $M_{\mathrm{w}}$ of PCL is equal to $71,220 \mathrm{~g} / \mathrm{mol}$ and its polydispersity index is equal to 1.69. It has been shown that the polymers forming the mixture are immiscible. DSC and tensile tests confirm the compatibility of the blend. In addition, this mixture displays a ductile character. Then, shape memory tests are performed. It has been revealed that, for these properties, the (40\% PCL/60\% SBS) blend has a TSME, as it recovers $100 \%$ of its permanent shape under thermal trigging. Afterwards, enzymatic hydrolysis is used as a proceeding to vary the $M_{\mathrm{w}}$ of PCL. $M_{\mathrm{w}}$ of PCL decreases with hydrolysis time. The diminution of the PCL $M_{\mathrm{w}}$ engenders the reduction in chain lengths, the decrease in the entanglement density, the increase in $X_{\mathrm{c}}$, the drop of the elongation to break and the rise of both glass transition and melting temperatures. Subsequently, SM tests are carried out on blends with different values of PCL $M_{\mathrm{w}}$, hence the different physico-chemical properties. It has been shown that the SME of the SMP mixture decreases, since $R_{\mathrm{r}}$ goes down, when $M_{\mathrm{w}}$ of PCL drops. This result could be associated to the shortening of chains, the drop of the entanglement degree, the embrittlement of the structure, and the decline in the compatibility and homogeneity of the blend components. We have reported that the SME does not only concern macroscopic changes but it results from a combination of the polymer $M_{\mathrm{w}}$ and its internal properties. We have also revealed that by varying the $M_{\mathrm{w}}$ of one of the SMP blend components, a range of new blends with different SMEs are created. The (SBS/PCL) mixture is transformed from a TSME polymer into a PSME one. The establishment of a relationship between the SMP physiochemistry and its SME will be necessary to better apprehend its evolution in order to meet specific uses and applications.

\section{CONFLICT OF INTEREST}

The authors declare no conflicts of interest.

\section{ORCID}

\section{Abir Ben Abdallah (1) https://orcid.org/0000-0002-4164-} 369X

\section{REFERENCES}

[1] Q. Meng, J. Hu, Compos.: Part A 2009, 40, 1661.

[2] S. Farzaneh, J. Fitoussi, A. Lucas, M. Bocquet, A. Tcharkhtchi, J Appl. Polym. Sci. 2012, 28, 3240.

[3] M. Behl, A. Lendlein, Mater. Today 2007, 10, 20.

[4] Q. H. Meng, J. L. Hu, Y. Zhu, J. Lu, Y. Liu, Smart Mater. Struct. 2007, 16, 1192.

[5] J. L. Hu, X. M. Ding, X. M. Tao, J. China Text. Univ. 2002, 19, 89.
[6] J. Karger-Kocsis, J. Mater. Sci. 2008, 43, 254.

[7] T. Xie, Polymer 2011, 52, 4985.

[8] A. Tcharkhtchi, S. Abdallah-Elhirtsi, K. Ebrahimi, J. Fitoussi, M. Shirinbayan, S. Farzaneh, Polymer 2014, 6, 1144.

[9] H. Zhang, H. Wang, W. Zhong, Q. Du, Polymer 2009, 50, 1596.

[10] Ben Abdallah A, Kallel A, Gamaoun F, presented at 7th Int. Congress Design and Modeling of Mechanical Systems, Tunisia, 2017.

[11] A. Lendlein, S. Kelch, Angew. Chem. Int. 2002, 41, 2034.

[12] R. Biju, C. P. Reghunadhan Nair, High Perform. Polym. 2013, $25,464$.

[13] L. Sun, W. M. Huang, Soft Matter. 2010, 6, 4403.

[14] B. S. Lee, B. C. Chun, Y. C. Chung, K. Sul, Macromolecules I 2001, 34, 6431.

[15] M. Hakkarainen, A. C. Albertsson, S. Karlsson, Polym. Degrad. Stabil. 1996, 52, 283.

[16] M. Hakkarainen, A. C. Albertsson, Adv. Polym. Sci. 2008, 211, 85.

[17] P. Rizzarelli, G. Impallomeni, G. Montaudo, Biomacromolecules 2004, 5, 433.

[18] H. Tsuji, T. Ishizaka, Int. J. Biol. Macromol. 2001, 29, 83.

[19] L. Tilstra, D. Johnsonbaugh, J. Environ. Polym. Deg. 1993, $1,257$.

[20] I. Castilla-Cortázar, J. Más-Estellés, J. M. Meseguer-Dueñas, J. L. Escobar Ivirico, B. Marí, A. Vidaurre, Polym. Degrad. Stabil. 2012, 97, 1241.

[21] S. Malberg, A. Hoglund, A. C. Albertsson, Biomacromolecules 2011, 12, 2382.

[22] S. Li, L. Liu, H. Garreau, M. Vert, Biomacromolecules 2003, $4,372$.

[23] Z. Gan, Q. Liang, J. Zhang, X. Jing, Polym. Degrad. Stabil. 1997, 56, 209.

[24] H. Tsuji, K. Ikarashi, Polym. Degrad. Stabil. 2004, 85, 647.

[25] H.-G. Elias, Macromolecules 1977, 1, 297.

[26] S. A. Umoren, M. M. Solomon, Polym. Sci. 2016, 412.

[27] A. Singh, Int. J. Technol. 2019, 8, 61.

[28] T. Elzein, M. Nasser-Eddine, C. Delaite, S. Bistac, P. Dumas, J. Colloid Int. Sci. 2004, 273, 381.

[29] B. Fayolle, X. Colin, L. Audouin, J. Verdu, Polym. Degrad. Stabil. 2007, 92, 231.

[30] D. M. Shinozaki, K. Woo, J. Vlachopoulos, A. Hamielec, J. Appl. Polym. Sci. 1977, 21, 3345.

[31] G. Capaccio, I. M. Ward, Polym. Eng. Sci. 1975, 15, 219.

[32] T. C. B. Mc LEISH, Adv. Phys. 2002, 1, 1379.

[33] A. B. Abdallah, A. Kallel, F. Gamaoun, A. Tcharkhtchi, J. Polym. Environ. 2019, 27, 2341.

[34] V. Massardier, Etat de l'art concernant la compatibilité des matières plastiques, INSA de Lyon, France 2001.

[35] T. Xie, Polymer 2011, 52, 4985.

[36] R. W. Nunes, J. R. Martin, J. F. Johnson, Polym. Eng. Sci. 1982, 22, 205.

[37] H. Tsuji, T. Ishizaka, Int. J. Biol. Macromol. 2001, 29, 83.

[38] B. Fayolle, E. Richaud, X. Colin, J. Verdu, J. Mater. Sci. 2008, 43, 6999.

[39] A. Riley, Packag. Technol. 2012, 12, 262.

[40] A. F. Margolies, Soc. Pet. Eng. J. 1971, 27, 44. 
[41] S. Abdallah-Elhirtsi, J. Fitoussi, B. J. Rashmi, K. Prashantha, S. Farzaneh, M. F. Lacrampe, P. Krawczak, A. Tcharkhtch, Polym. Compos. 2015, 36, 1145.

[42] M. Ahmad, B. Xu, H. Purnawali, Y. Fu, W. Huang, M. Miraftab, J. Luo, Appl. Sci. 2012, 2, 535.

[43] B. S. Lee, B. C. Chun, Y. C. Chung, K. I. Sul, J. W. Cho, Macromolecules 2001, 34, 6431. 